\title{
Immune-surveillance and programmed cell death-related genes are significantly overexpressed in the normal breast epithelium of postmenopausal parous women
}

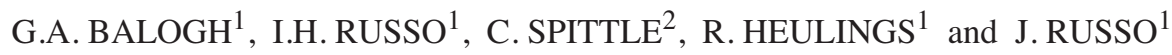 \\ ${ }^{1}$ Breast Cancer Research Laboratory, and ${ }^{2}$ Biomarker and Genotyping Facility, \\ Fox Chase Cancer Center, Philadelphia, PA, USA
}

Received February 23, 2007; Accepted May 4, 2007

\begin{abstract}
Endocrine and reproductive influences significantly affect the lifetime risk of breast cancer. Nulliparity is one of the most firmly established risk factors for breast cancer, whereas early full-term pregnancy and parity confer a significant protection. The breast attains its maximum development during pregnancy and lactation. After menopause the breast regresses in both nulliparous and parous women containing lobular structures designated lobules type 1 (Lob 1). We have postulated that the degree of differentiation acquired through early pregnancy changes the 'genomic signature' that differentiates the Lob 1 from the early parous women from that of the nulliparous women by shifting the Stem cell 1 to a Stem cell 2, making this the mechanism of protection conferred by early full-term pregnancy. In order to elucidate the molecular pathways through which pregnancy exerts a protective effect, we have analyzed the genomic profile of Lob 1 present in reduction mammoplasty specimens obtained from parous and nulliparous postmenopausal women. The genes differentially expressed are related to immune-surveillance, DNA repair, programmed cell death, transcription, and chromatin structure/ activators/co-activator. In the present study we performed real-time RT-PCR using a low-density array or a microfluid card for genes related to the immune system and programmed cell death, using $18 \mathrm{~S}$ as an internal control [TaqMan ${ }^{\circledR}$ Low Density Array Human Immune Panel (Applied Biosystems)]. Breast epithelial cells from parous women significantly overexpressed 17 out of 20 genes $(p<0.001)$ with respect to the nulliparous breast. BCL2-associated X protein, Complement component 3, CD45 antigen, glyceraldehyde-3-phosphate dehydrogenase, granulysin, and chemokine (C-C motif)
\end{abstract}

Correspondence to: Dr Jose Russo, Breast Cancer Research Laboratory, Fox Chase Cancer Center, 333 Cottman Ave., Philadelphia, PA 19111, USA

E-mail: J_russo@fccc.edu

Key words: immune-surveillance genes, microfluid card, postmenopausal breast, laser capture microdissection, pregnancy, prevention ligand 19 were expressed more than 30-fold with respect to nulliparous breast cells. Only three out of 20 genes [selectin P (granule membrane protein $140 \mathrm{kDa}$, antigen CD62), Fas (TNF receptor superfamily, member 6 ) and chemokine (C-X-C motif) ligand 11], were downregulated in parous breast with respect to nulliparous breast cells. The data lead us to conclude that an early pregnancy, by shifting the Stem cell 1 to Stem cell 2 , makes the latter more easily recognized by the immunesurveillance system, which initiates the programmed cell death pathway if exposure to toxic or carcinogenic agents occurs.

\section{Introduction}

Early pregnancy imprints in the breast permanent genomic changes or a 'signature' that reduces the susceptibility of this organ to cancer (1-3). The breast attains its maximum development during pregnancy and lactation and after menopause the breast regresses in both nulliparous and parous women containing lobular structures designated Lob $1(4,5)$. The Lob 1 found in the breast of nulliparous women and of parous women with breast cancer never went through the process of differentiation, retaining a high concentration of epithelial cells that are targets for carcinogens and therefore susceptible to undergo neoplastic transformation, these cell are called Stem cells 1, whereas Lob 1 structures found in the breast of early parous postmenopausal women free of mammary pathology, on the other hand, are composed of an epithelial cell population that is refractory to transformation called Stem cells 2 (6-8). The degree of differentiation acquired through early pregnancy changes the 'genomic signature' that differentiates the Lob 1 from the early parous women from that of the nulliparous women by shifting the Stem cell 1 to a Stem cell 2 (1-3). Those genes that were significantly different are related to immune-surveillance, DNA repair, programmed cell death, transcription, and chromatin structure/activators/ co-activator (1-3). Among the genes related to immunesurveillance we found the cytoplasmic Toll/interleukin-1 receptor (TIR), the $\mathrm{T}$ cell receptor $\mathrm{V}-\beta 1$ (TCRB), the MHC class I HLA-A24 and the interleukin 22 receptor (IL22) (1-3). The BCL2-associated X protein, which has the function of regulating the programmed cell death process, was also significantly upregulated in the epithelia of the parous postmenopausal breast. This group of gene transcripts could be 


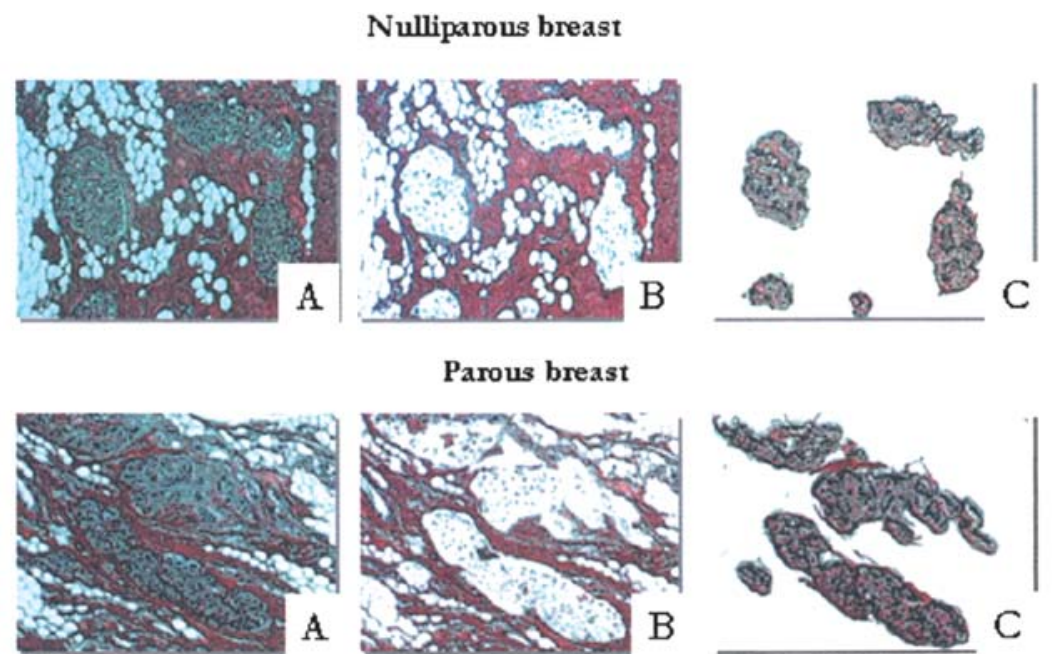

Figure 1. Normal breast epithelial cells dissected by laser capture microdissection (LCM). The ductal epithelial cells of the tissue of postmenopausal nulliparous and parous breast were separated from the stroma. A, breast tissue before LCM; B, after LCM; C, cells captured from which the RNA was extracted. Stained with hematoxylin and eosin; magnification, x10.

Table I. RNA amplified from the LCM cells of parous and nulliparous breast.

\begin{tabular}{rcccccc}
\hline Patient no. & Reproductive history & Type of cell capture & No. of cells captured by LCM & RNA (ng/ $\mu$ l) & aRNA (ng/ $\mu 1)$ & aaRNA (ng/ $\mu 1)$ \\
\hline \multirow{2}{*}{641} & Parous & Epithelium & 849 & 12.8 & 105.0 & 1927.3 \\
387 & Parous & Epithelium & 1,544 & 23.3 & 178.0 & 1284.0 \\
3302 & Parous & Epithelium & 1,412 & 21.3 & 97.0 & 1080.0 \\
33 & Parous & Epithelium & 1,525 & 23.0 & 208.0 & 1260.0 \\
104926 & Nulliparous & Epithelium & 1,424 & 21.49 & 193.0 & 2026.0 \\
426 & Nulliparous & Epithelium & 2,630 & 39.68 & 138.0 & 1536.0 \\
527 & Nulliparous & Epithelium & 2,466 & 37.2 & 57.4 & 892.0 \\
\hline
\end{tabular}

an indication that immune-surveillance and programmed cell death could play an important role in the genomic signature induced by pregnancy and therefore in the mechanism that this physiological process plays in the protection against breast cancer.

In order to expand these observations we studied the expression profiles of 20 genes related to the immune system and programmed cell death employing the TaqMan ${ }^{\circledR}$ lowdensity array human immune panel (Applied Biosystems).

\section{Materials and methods}

Tissue samples. This study was carried out using normal breast tissues obtained from reduction mammoplasties that were performed for cosmetic reasons in postmenopausal parous and nulliparous women. The parous group consisted of four postmenopausal women free of mammary pathology who had completed a first full-term pregnancy (FFTP) before the age of 24 years. They ranged in age from 56 to 60 years. The nulliparous group consisted of three postmenopausal women that were in the same age range. Postmenopause was defined as previously described (3). Each sample was obtained after each donor had signed their respective informed consent forms that were approved by the Fox Chase Cancer Center's Human Subjects Protection Committee. The breast tissues were fixed in $70 \%$ ethanol within 10 min of the surgical procedure. The tissues were dehydrated, embedded in paraffin, sectioned at five-micron thickness and stained with hematoxylin and eosin, followed by 5-sec dehydration steps in 70, 95 and $100 \%$ ethanol. One section was coverslipped for evaluation of the development of the breast following criteria described previously (4). Additional sections were air-dried and laser microdissected using an AutoPix 1000 LCM system (Arcturus Engineering, Mountain View, CA). Epithelial cells from Lob 1 were obtained in sixtuplicate from each breast sample (Fig. 1).

RNA isolation from the LCM. Total RNA was isolated using Trizol (Invitrogen, Inc.) separately for each capture and then pooled for each breast sample. The total RNA was amplified using a method based on dT-T7-RNA amplification (3). The amplification procedure involved four steps, the first one was the cDNA synthesis using the RT enzyme (Superscript from Invitrogen), the second step was the amplification based on dT-T7 and switch T7 primers, the third step consisted of the in vitro transcription reaction and the last one was the RNA purification and quantification. The concentration of RNA before and after amplification are depicted in Table I. The concentration and the quality of the pooled RNA were measured using a spectrophotometric method (Nanodrop Technologies, Inc.). 
Table II. RT-PCR values of the genes expressed in the nulliparous and parous breast epithelial cells

\begin{tabular}{llcrrrrr}
\hline Sample & Gene name & Gene symbol & Assay ID & Avg $\Delta$ Ct & $\Delta$ Ct S.D. & $\Delta \Delta C t$ & RQ \\
\hline Nulliparous breast cells & 18S & 18S & Hs99999901_s1 & 0.0000 & 0.0000 & \\
Parous breast cells & 18S & $18 \mathrm{~S}$ & Hs99999901_s1 & 0.0000 & 0.0000 & \\
Nulliparous breast cells & BCL2-associated X protein & BAX & Hs00180269_m1 & 14.1494 & 0.0000 & 0.000 & 1.000 \\
Parous breast cells & BCL2-associated X protein & BAX & Hs00180269_m1 & 8.5533 & 0.6322 & -5.596 & 48.373 \\
Nulliparous breast cells & Complement component 3 & C3 & Hs00163811_m1 & 14.1494 & 0.0000 & 0.000 & 1.000 \\
Parous breast cells & Complement component 3 & C3 & Hs00163811_m1 & 8.8711 & 0.5156 & -5.278 & 38.807 \\
Nulliparous breast cells & chemokine (C-C motif) receptor 4 & CCR4 & Hs99999919_m1 & 7.8698 & 0.4545 & 0.000 & 1.000 \\
Parous breast cells & chemokine (C-C motif) receptor 4 & CCR4 & Hs99999919_m1 & 6.6113 & 0.3076 & -1.258 & 2.392 \\
Nulliparous breast cells & CD34 antigen & CD34 & Hs00156373_m1 & 14.1494 & 0.0000 & 0.000 & 1.000 \\
Parous breast cells & CD34 antigen & CD34 & Hs00156373_m1 & 9.5434 & 0.6394 & -4.606 & 24.353 \\
Nulliparous breast cells & CD45 antigen & CD45 & Hs00365634_g1 & 14.1494 & 0.0000 & 0.000 & 1.000 \\
Parous breast cells & CD45 antigen & CD45 & Hs00365634_g1 & 8.4862 & 0.1449 & -5.663 & 50.676 \\
Nulliparous breast cells & selectin P (granule membrane protein & CD62E & Hs00174583_m1 & 9.4160 & 0.6565 & 0.000 & 1.000 \\
& 140 kDa, antigen CD62) & (SELP) & & & & \\
Parous breast cells & selectin P (granule membrane protein & CD62E & Hs00174583_m1 & 13.2384 & 0.1013 & 3.822 & 0.071 \\
& 140 kDa, antigen CD62) & (SELP) & & & & \\
Nulliparous breast cells & Collagen IV & COL4A5 & Hs00166712_m1 & 9.6272 & 0.3732 & 0.000 & 1.000 \\
Parous breast cells & Collagen IV & COL4A5 & Hs00166712_m1 & 8.8521 & 0.3142 & -0.775 & 1.711 \\
Nulliparous breast cells & prostaglandin-endoperoxide synthase 2 & PTGS2 & Hs00153133_m1 & 10.6659 & 0.0268 & 0.000 & 1.000
\end{tabular}

Parous breast cells (prostaglandin $\mathrm{G} / \mathrm{H}$ synthase and cyclooxygenase)

PTGS2 Hs00153133_m1 $8.1526 \quad 0.5189 \quad-2.513 \quad 5.709$ (prostaglandin $\mathrm{G} / \mathrm{H}$ synthase and cyclooxygenase)

Nulliparous breast cells endothelin 1

Parous breast cells endothelin 1

Nulliparous breast cells Fas (TNF receptor superfamily, member 6)

Parous breast cells $\quad$ Fas (TNF receptor superfamily, member 6)

Nulliparous breast cells fibronectin 1

Parous breast cells fibronectin 1

Nulliparous breast cells glyceraldehyde-3-phosphate dehydrogenase

Parous breast cells glyceraldehyde-3-phosphate dehydrogenase

Nulliparous breast cells granulysin

Parous breast cells granulysin

Nulliparous breast cells glucuronidase, $\beta$

Parous breast cells glucuronidase, $\beta$

Nulliparous breast cells major histocompatibility complex, class II, $\mathrm{DR} \alpha$

Parous breast cells major histocompatibility complex, class II, DR $\alpha$

Nulliparous breast cells interleukin 1 B

Parous breast cells interleukin $1 \mathrm{~B}$

Nulliparous breast cells interleukin 8

Parous breast cells interleukin 8

Nulliparous breast cells chemokine (C-X-C motif) ligand 11

Parous breast cells chemokine (C-X-C motif) ligand 11

$\begin{array}{clrrrr}\text { EDN1 } & \text { Hs00174961_m1 } & 10.4343 & 0.5787 & 0.000 & 1.000 \\ \text { EDN1 } & \text { Hs00174961_m1 } & 8.5029 & 0.3341 & -1.931 & 3.814 \\ \text { Fas } & \text { Hs00163653_m1 } & 9.7610 & 0.3392 & 0.000 & 1.000 \\ \text { Fas } & \text { Hs00163653_m1 } & 13.2384 & 0.1013 & 3.477 & 0.090 \\ \text { FN1 } & \text { Hs00365052_m1 } & 14.1494 & 0.0000 & 0.000 & 1.000 \\ \text { FN1 } & \text { Hs00365052_m1 } & 9.4166 & 0.2851 & -4.733 & 26.589 \\ \text { GAPDH } & \text { Hs99999905_m1 } & 14.1494 & 0.0000 & 0.000 & 1.000 \\ \text { GAPDH } & \text { Hs99999905_m1 } & 8.8243 & 0.4063 & -5.325 & 40.087 \\ \text { GNLY } & \text { Hs00246266_m1 } & 14.1494 & 0.0000 & 0.000 & 1.000 \\ \text { GNLY } & \text { Hs00246266_m1 } & 9.2064 & 1.0091 & -4.943 & 30.760 \\ \text { GUSB } & \text { Hs99999908_m1 } & 7.8967 & 0.5131 & 0.000 & 1.000 \\ \text { GUSB } & \text { Hs99999908_m1 } & 6.8156 & 0.5129 & -1.081 & 2.116 \\ \text { HLA-DRA } & \text { Hs00219575_m1 } & 4.9393 & 0.1417 & 0.000 & 1.000 \\ & & & & & \\ \text { HLA-DRA } & \text { Hs00219575_m1 } & 3.1334 & 0.1589 & -1.806 & 3.497 \\ & & & & & \\ \text { IL1B } & \text { Hs00174097_m1 } & 9.5770 & 0.4217 & 0.000 & 1.000 \\ \text { IL1B } & \text { Hs00174097_m1 } & 7.2934 & 0.6072 & -2.284 & 4.869 \\ \text { IL8 } & \text { Hs00174103_m1 } & 14.1491 & 0.0000 & 0.000 & 1.000 \\ \text { IL8 } & \text { Hs00174103_m1 } & 7.8921 & 0.6049 & -6.257 & 76.497 \\ \text { CXCL11 } & \text { Hs00171138_m1 } & 8.8580 & 0.7478 & 0.000 & 1.000 \\ \text { CXCL11 } & \text { Hs00171138_m1 } & 8.9178 & 0.1581 & 0.060 & 0.959 \\ \text { CCL19 } & \text { Hs00171149_m1 } & 14.1494 & 0.0000 & 0.000 & 1.000 \\ \text { CCL19 } & \text { Hs00171149_m1 } & 8.7052 & 0.5088 & -5.444 & 43.538 \\ \text { CCL5 } & \text { Hs00174575_m1 } & 9.4034 & 1.8346 & 0.000 & 1.000 \\ \text { CCL5 } & \text { Hs00174575_m1 } & 5.9424 & 0.3791 & -3.461 & 11.012 \\ & & & & & \end{array}$

Nulliparous breast cells chemokine (C-C motif) ligand 19

Parous breast cells chemokine (C-C motif) ligand 19

Nulliparous breast cells chemokine (C-C motif) ligand 5

Parous breast cells chemokine (C-C motif) ligand 5

Column 1 represents the tissue type; column 2 depicts the name of the genes available in the microfluid card; column 3 contains the gene symbol; column 4 shows the assay ID of the specific probes + primers commercially available from ABI Systems; column 5 represents the average of the $\Delta \mathrm{Ct}$ (the difference in the $\mathrm{Ct}$ values between each gene and the control gene used, in this case 18S); column 6 represents the standard deviation of $\Delta \mathrm{Ct}$ values, from three replicates; column 7 represents the $\Delta \Delta \mathrm{Ct}$ value (the difference in the $\Delta \mathrm{Ct}$ from each gene in the parous women with respect to the expression of the same gene in nulliparous breast tissue). The last column represents the relative quantitation of the gene expression ( $2^{\wedge}-\Delta \Delta \mathrm{Ct}$; the $\log$ base 2 of $\Delta \Delta \mathrm{Ct}$ values). 


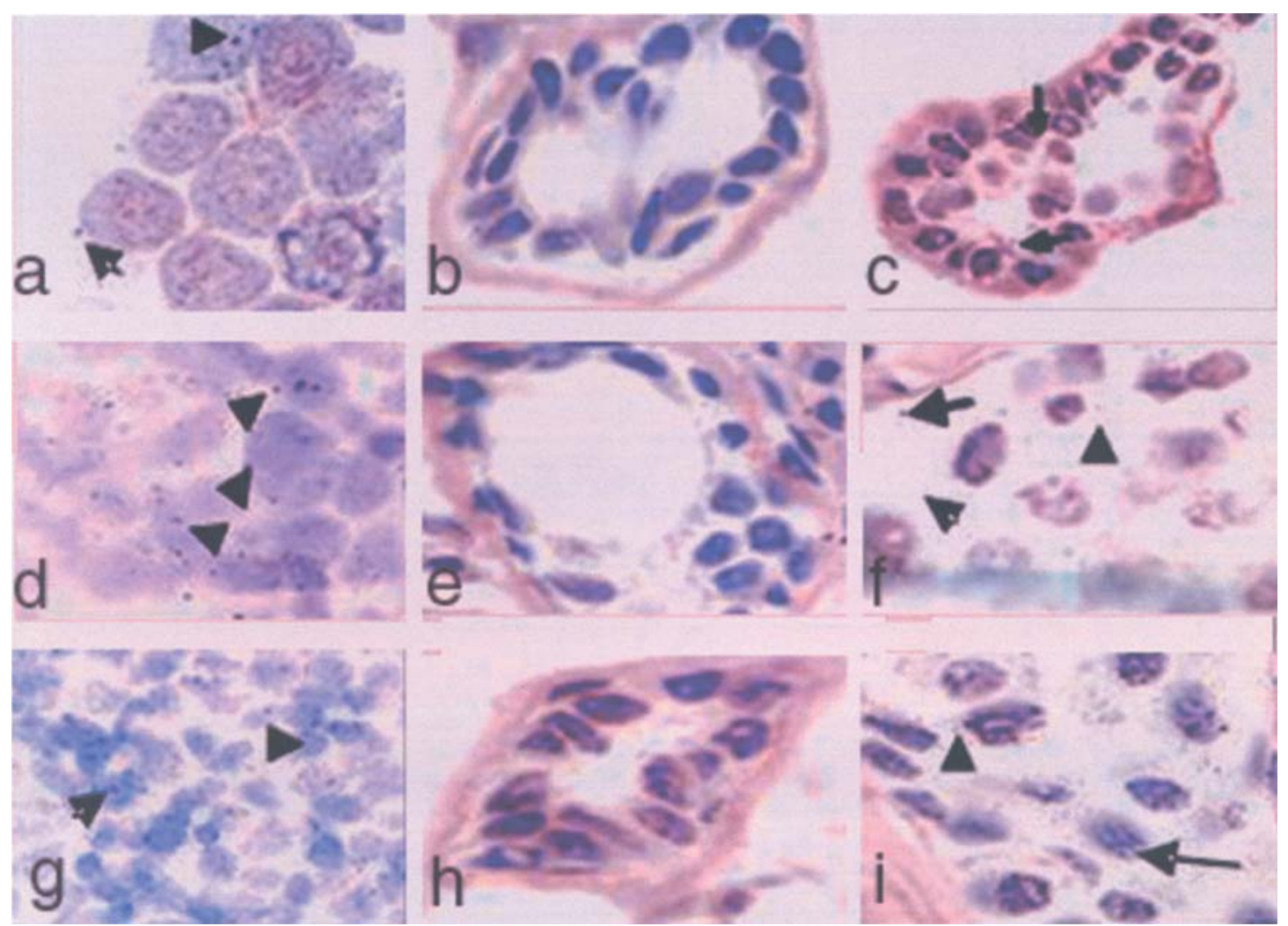

Figure 2. Immunocytochemical reaction of IL8; CD45 and CD34 in the control cells, nulliparous and parous breast tissue. (a) Molt 4 cells, control for IL8; (b) nulliparous breast stained with anti-IL8; (c) parous breast stained with anti-IL8; (d) Jurkat cells, control for CD45; (e) nulliparous breast stained with antiCD45; (f) parous breast stained with anti-CD45; (g) Jurkat cells, control for CD34; (h) nulliparous breast stained with anti-CD34; and (i) parous breast stained with anti-CD34. Magnification, $\mathrm{x} 40$.
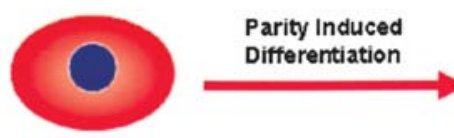

Stem Cell 1

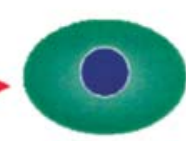

Stem Cell 2

$\left\{\begin{array}{l}\text { BAX } \\ \text { GAPDH } \\ \text { GNLY } \\ \text { Fas } \\ \text { C 3 } \\ \text { HLA-DRA } \\ \text { CD34 } \\ \text { CD45 } \\ \text { CCL19 } \\ \text { CCL5 } \\ 118 \\ 118 \\ \text { FN1 } \\ 118\end{array}\right.$

Figure 3. Schematic representation of the pregnancy-induced differentiation in which Stem cell 1 is shifted to Stem cell 2. The genes listed are part of the signature of Stem cell 2.

Gene expression analysis. We performed quantitative real-time RT-PCR using the TaqMan ${ }^{\circledR}$ low-density array human immune panel (Applied Biosystems) containing primer and probe sets for the detection of 96 genes related to the immune system and programmed cell death and $18 \mathrm{~S}$ as an internal control. All RT-PCR reactions were performed on the ABI Prism ${ }^{\circledR}$ 7900HT sequence detection system (Applied Biosystems) using the fluorescent TaqMan ${ }^{\circledR}$ methodology. TaqMan One Step RT PCR Master mix (Applied Biosytems) and $100 \mathrm{ng}$ of aaRNA were used for each RT-PCR reaction in a final volume of $100 \mu \mathrm{l}$. The thermal cycling conditions comprised $30 \mathrm{~min}$ at $48^{\circ} \mathrm{C}, 10 \mathrm{~min}$ at $95^{\circ} \mathrm{C}$ and 40 cycles of $15 \mathrm{sec}$, denaturation at $95^{\circ} \mathrm{C}$ and $60-\mathrm{sec}$ annealing at $60^{\circ} \mathrm{C}$. Each gene was analyzed in duplicate, normalized against $18 \mathrm{~S}$ as a control gene and expressed relative to a calibrator sample, as described by Livak and Schmittgen (9) and Benoy et al (10). The PCR cycle at which the fluorescence rises above the background signal is called the cycle threshold $(\mathrm{Ct})$. The results are expressed as relative gene expression (RGE) using the $\Delta \mathrm{Ct}$ method. We used the $\Delta \mathrm{Ct}$ method to quantify our results. To adopt this calculation method, the amplification efficiencies of the target genes and endogenous control gene (18S) have to be comparable. $\Delta \mathrm{Ct}$ values are obtained by calculating $\mathrm{Ct}$ values of the target genes minus the $\mathrm{Ct}$ values of $18 \mathrm{~S}$ in each condition, then we performed antilog base 2 .

Immunohistochemistry assay. Tissues fixed in formalin, dehydrated, and embedded in paraffin were cut at $5-\mu \mathrm{m}$ thickness and stained with hematoxylin and eosin for histopathological analysis. For immunocytochemical analysis tissue sections were mounted on aminoalkylsilane-coated or positively charged slides, deparaffinized, rehydrated and incubated in $2 \%$ hydrogen peroxide at room temperature for $15 \mathrm{~min}$ for quenching endogenous peroxidase activity. The sections were sequentially incubated in two changes of Target Retrieval Solution at $98^{\circ} \mathrm{C}$ for $5 \mathrm{~min}$ each. All the tissue sections were incubated in diluted normal blocking serum for $20 \mathrm{~min}$. Excess serum was blotted from the slides and the sections were incubated with the following antibodies: mouse monoclonal antibodies IL8 (B-2, sc-8427), CD45 (35-Z6, sc-1178), and CD34 (IC0115, sc7324) (Santa Cruz Biotechnology, Inc, CA). Citospin from Molt-4 and Jurkat 
cultured cells were used as positive control. The antibodies (diluted 1:50) were incubated overnight at $4^{\circ} \mathrm{C}$ and DABnickel staining was employed to develop the immunoreaction. All sections were lightly counterstained with hematoxylin. Immunostaining was evaluated by examination of slides under a bright field microscope, and graded positive if a dark stippled reaction was present.

\section{Results}

In Table II are shown the data of relative gene expression (RQ) from parous and nulliparous breast epithelial cells indicating that 17 out of 20 genes were overexpressed in parous breast cells with respect to nulliparous breast cells, or relative quantitation $(\mathrm{RQ})>1.7$ (last column of Table II). Among these the BCL2-associated X protein, Complement component 3, CD45 antigen, glyceraldehyde-3-phosphate dehydrogenase, granulysin, and chemokine (C-C motif) ligand 19 were expressed $>30$-fold with respect to nulliparous breast cells. Only three out of 20 genes [selectin P (granule membrane protein $140 \mathrm{kDa}$, antigen CD62), Fas (TNF receptor superfamily, member 6 ) and chemokine (C-X-C motif) ligand 11], were downregulated in parous breast with respect to nulliparous breast cells (Table II).

We have confirmed by immunohistochemistry the protein expression of IL8, CD45 and CD34 in the breast tissues from parous postmenopausal women. The localization of these proteins was intracytoplasmic as a fine granular reaction similar to the one detected in the positive control cells (Fig. 2). We did not observe immunocytochemical reactivity in similar structures in the nulliparous breast epithelia (Fig. 2).

\section{Discussion}

In the present study, we show that the breast epithelia of parous postmenopausal breast overexpressed seventeen genes that are related to immune-surveillance and programmed cell death. These data support our previous observations that the breast epithelial cells of the lobules type 1 found in the breast tissue of postmenopausal parous women has a genomic signature different from similar structures derived from postmenopausal nulliparous women (1-3). After the postmenopausal involution of the mammary gland, the architecture of the parous breast is similar to that of the nulliparous breast, containing predominantly Lob 1 that is refractory to transformation. It was further postulated that the degree of differentiation acquired through early pregnancy permanently changes the genomic signature that differentiates the Lob 1 from early parous women from that of nulliparous women, shifting the Stem cell 1 to a Stem cell 2 that is refractory to carcinogenesis. These cells were called Stem cells 2 because after postlactational involution, the mammary epithelium remains capable of responding with proliferation and differentiation to the stimulus of a new pregnancy; however, these cells are refractory to carcinogenesis, even though they are stimulated to proliferate and to regenerate the whole mammary gland (1-3). The Stem cell 2 is characterized by having a genomic signature that has been induced by the first cycle of differentiation. Those genes that are significantly different are grouped in major categories based on their putative functional significance such as immune-surveillance, DNA repair, programmed cell death, and genomic transcription, chromatin structure/activators/co-activators (1-3,11-14).

The genes controlling programmed cell death that were differentially expressed in the parous breast epithelia are the BCL2-associated X protein, glyceraldehyde-3-phosphate dehydrogenase, granulysin and the Fas (TNF receptor superfamily member 6) (TNFRSF6). The BCL2-associated protein or BAX protein encoded by this gene belongs to the BCL2 protein family (15). BAX is a pro-apoptotic gene that the active p53 stimulates the transcription of it, including the pro-apoptotic gene $\mathrm{p} 21$, a cell cycle regulator (15-18). The role of BAX in breast cancer is not clear $(19,20)$ and similar levels of expression were identified in normal tissues (20-22). In a BAX-expressing breast cancer cell line transplanted into SCID mice, although tumor growth could not be completely prevented, Bax expression led to a significant reduction of tumor growth (23). In the parous breast, the BCL2-associated $\mathrm{X}$ protein is upregulated in the epithelial cells and is part of its genomic signature. Supporting evidence to this finding comes from a rat experimental model in which post-pregnancy involuted mammary gland exhibits a genomic signature characterized by elevated expression of genes involved in programmed cell death pathways. Among the genes controlling this process are the testosterone repressed prostate message 2 (TRPM2), interleukin 1ß-converting enzyme (ICE), bcl-XL, bcl-XS, p53, p21, and c-myc, which can be from 3- to 5-fold upregulated (12-14). In the present study we have found that the glyceraldehyde-3-phosphate dehydrogenase (GAPDH) is upregulated 40-fold in parous compared with nulliparous epithelia. GAPDH plays an important role in glycolysis and gluconeogenesis $(24,25)$ by reversibly catalysing the oxidation and phosphorylation of D-glyceraldehyde-3-phosphate to 1,3-diphosphoglycerate. The enzyme has been found to bind to actin and tropomyosin, and may thus have a role in cytoskeleton assembly (25). GAPDH displays diverse nonglycolytic functions as well, its role depending upon its subcellular location. For instance, the translocation of GAPDH to the nucleus acts as a signalling mechanism for programmed cell death, or apoptosis (26). The accumulation of GAPDH within the nucleus is involved in the induction of apoptosis, where GAPDH functions in the activation of transcription. The presence of GAPDH is associated with the synthesis of pro-apoptotic proteins such as BAX, c-JUN and GAPDH itself. Therefore the overexpression of GAPDH in the parous breast together with BAX strongly suggest that the parous epithelia or Stem cell 2 have a different pro-apoptotic pathway that makes them more vulnerable to apoptosis if an exogenous insult takes place. Further support to this contention is that the parous breast expresses granulysin that is upregulated 30-fold. Granulysin, a lytic molecule expressed by human cytolytic T lymphocytes and natural killer cells, is colocalized in granules with perforin and granzymes and is active against tumor cells and a variety of microbes, including Mycobacterium tuberculosis (27-30). Recombinant 9-kDa granulysin disrupts artificial liposomes and cell membranes, damages mitochondria, and activates caspase-9 to induce apoptosis in nucleated cells but does not lyse red blood cells (31). The 9-kDa granulysin contains two disulfide bonds, and reduction of recombinant granulysin enhances its lytic activity against 
tumor targets but does not affect its activity against bacteria (32). Peptides corresponding to the central region of granulysin lyse bacteria, human cells, and synthetic liposomes, while peptides corresponding to the amino or carboxyl regions are not lytic (32). Most peptides corresponding to either helix 2 or helix 3 lyse bacteria, while lysis of human cells and liposomes is dependent on the helix 3 sequence. Peptides in which positively charged arginine residues were replaced by neutral glutamine exhibit reduced lysis of all three targets (32). Granulysin and its constituent peptides bind to the cell surface based on charge and cause an increase in the intracellular $\mathrm{Ca}^{2+}$ concentration and a subsequent decrease in the intracellular $\mathrm{K}^{+}$concentration $(31,33)$. Both calcium and potassium channel blockers inhibit granulysin/peptide-induced apoptosis in tumor cells (33). The rise in $\left[\mathrm{Ca}^{2+}\right](\mathrm{i})$ precedes a decrease in intracellular $\mathrm{K}^{+}$, and elevated extracellular $\mathrm{K}^{+}$prevents granulysin-mediated cell death. In granulysin-treated cells, electron transport is uncoupled, and reactive oxygen species are generated. Finally, an increase in intracellular glutathione protects target cells from granulysin-induced lysis, indicating the importance of the redox state in granulysin-mediated cell death. Exogenously added granulysin kills HeLa target cells by entering the nucleus and inducing apoptosis (34). Whereas no reports have been found on the role of this gene product in breast tissue, its high expression in the parous breast together with the BCL2-associated X protein, and GAPDH that are controlling programmed cell death may explain a specific function in the differentiated breast epithelia. There is supporting data indicating that granulysin could play an important preventive role, for example, in vivo effects of GNLY were evaluated using the syngeneic T lymphoma tumor C6VL (35). GNLY transgenic mice survived significantly longer than nontransgenic littermates in response to a lethal tumor challenge, suggesting that GNLY may prove a useful therapeutic modality for the treatment of cancer (35). We have shown that hCG is a preventive agent in the rat mammary gland supporting the knowledge that genes involved in the regulation of apoptosis were found to be also upregulated by gonadotrophin stimulation, including BAX inhibitor-1, granulysin and apoptosis repressor with caspase recruitment domain (ARC) (36). Tumor-free patients expressed granulysin at levels similar to healthy controls, while the progressive tumor-bearing patients expressed remarkably lower levels of granulysin compared to healthy controls $(\mathrm{P}<0.0001)$. Impaired expression of granulysin by NK cells correlates with progression of cancer, and determination of granulysin expression might prove informative for assessing the immunological condition of cancer patients (37).

A difference in the BCL2-associated X protein, glyceraldehyde-3-phosphate dehydrogenase, and granulysin was observed, and the Fas (TNF receptor superfamily member 6) (TNFRSF6) was downregulated 11-fold in the parous breast epithelia with respect to nulliparous breast epithelia. The FAS antigen shows structural homology with a number of cell surface receptors, including tumor necrosis factor (TNF) receptors $(38,39)$ and the low-affinity nerve growth factor receptor (NGFR). Functional expression studies in mouse cells showed that the FAS antigen induced antibody-triggered apoptosis. It has been shown (40) that the Fas antigen receptor was rapidly expressed on $\mathrm{T}$ cells following activation of $\mathrm{T}$ cell hybridomas, and that the interaction between FAS and FAS ligand (FASL, CD95L, or TNFSF6) induced cell death in a cell-autonomous manner consistent with apoptosis. Using mouse primary neurons and a human neuroblastoma cell line, it has been determined (41-43) that FAS can mediate neurite growth. Activation of FAS resulted in axon regeneration in primary neurons and accelerated functional recovery after sciatic nerve injury in vivo, by activating a nerve growth factorindependent signaling pathway that included activation of ERK and the expression of p35 (43). A potential protective effect induced by the downregulation of FAS emerged from the data of Song et al (44), who have investigated the in vivo silencing effect of small interfering RNA (siRNA) duplexes targeting the FAS gene to protect mice from liver failure and fibrosis in 2 models of autoimmune hepatitis. Hepatocytes isolated from these mice were resistant to apoptosis when exposed to Fas-specific antibody or cocultured with concanavalin-Astimulated hepatic mononuclear cells. Ma et al (45) observed that Fas-deficient (lpr/lpr) mice had less severe collageninduced arthritis, but higher levels of Illb in joints, than control mice, suggesting inefficient activation through Il1r1. All of these results indicate that the downregulation or silencing of FAS in the parous compared with the nulliparous epithelia could contribute to the signature of protection induced by parity (Fig. 3).

Complement component 3 or C3 and the major histocompatibility complex class II (HLA-DRA) are significantly highly expressed in parous breast epithelial cells with respect to breast epithelial cells from nulliparous women. Complement component $\mathrm{C} 3$ plays a central role in the activation of the complement system and its activation is required for both classical and alternative complement activation pathways. Complement components in breast milk may enhance the local immune response in the gut of infants and expression of C3 was upregulated in the gestational mammary gland (46) whereas in normal resting breast, only $\mathrm{C} 4 \mathrm{mRNA}$ was noted in some ductal epithelium (46). HLA-DRA was also upregulated more than three-fold in the parous epithelia and is one of the HLA class II $\alpha$ chain paralogues (47). It plays a central role in the immune system by presenting peptides derived from extracellular proteins. Class II molecules are expressed in antigen presenting cells (APC: B lymphocytes, dendritic cells, macrophages) (47). Although the exact role of C3 and HLA-DRA in the breast epithelium is unknown, we can postulate that these genes are specifically expressed after pregnancy in the ductal epithelium as part of the genomic signature of Stem cell 2. This may protect the breast tissue against cancer development by leaving the immune system ready to attack any proliferative cell with strange behavior in the breast epithelium, protecting the breast tissue against cell transformation or proliferation by inducing an inflammatory response and apoptosis (Fig. 3).

Two cell markers that are significantly upregulated in the parous epithelia are the CD34 and the CD45 antigens. CD34 antigen is a monomeric cell surface antigen with a molecular mass of approximately $110 \mathrm{kD}$ that is expressed on human hematopoietic progenitor cells (48-51) and small vessel endothelial cells (52). We have found that CD34 protein is also expressed in cultured breast epithelial cells from normal parous women by Western blot assay employing a specific monoclonal anti-CD34 antibody (data not shown). The specific 
band was observed in the parous breast epithelial cells and in the Jurkat cells employed as positive control (unpublished observation). We also observed by immunohistochemistry the expression of CD34 antigen in the normal breast epithelium from parous women employing the same antibody used for Western blotting.

The CD45 transcript is 50-fold overexpressed in the parous breast compared with the nulliparous epithelia and is immunohistochemically detected in the cytoplasm of these cells. CD45 antigen is an abundant hemopoietic-specific transmembrane protein tyrosine phosphatase (53). The phosphatase activity of CD45 Ag is crucial for efficient lymphocyte $\mathrm{Ag}$ receptor signal transduction, as has been shown in CD45-negative cell lines and CD45-deficient mice (53-57). CD45-knockout mice are severely immunodeficient. However, the role of expression of CD45 in the breast epithelia of parous women is unknown and can only be hypothesized to be protective surveillance of the epithelia or involved in the receptor signal transduction pathway.

There are six chemokines that are upregulated in the parous breast epithelia: chemokine, CC motif, ligand 19 (CCL19); chemokine, CC motif, ligand 5 (CCL5), chemokine, CC motif, receptor 4; chemokine, CXC motif, ligand 11 (CXCL11), interleukin 8 (IL8), and interleukin $1 ß$ (IL1ß). Chemokines are a group of small (approximately 8 to $14 \mathrm{kDa}$ ), mostly basic, structurally related molecules that regulate cell trafficking of various types of leukocytes through interactions with a subset of 7-transmembrane, G protein-coupled receptors. Chemokines also play fundamental roles in the development, homeostasis, and function of the immune system, and they have effects on cells of the central nervous system as well as on endothelial cells involved in angiogenesis or angiostasis. Chemokines are divided into 2 major subfamilies, CXC and CC, based on the arrangement of the first 2 of the 4 conserved cysteine residues; the 2 cysteines are separated by a single amino acid in CXC chemokines and are adjacent in CC chemokines (58-68).

The chemokine, CC motif, ligand 19 (CCL19) is more than 40-fold upregulated in the parous epithelia. This chemokine was cloned by Yoshida et al (58) and Rossi et al (59). Northern blot analysis revealed that the gene was expressed at high levels in thymus and lymph nodes, at intermediate levels in colon and trachea, and at low levels in spleen, small intestine, lung, kidney, and stomach. Robbiani et al (60) showed that migration of dendritic cells (DCs) from skin to lymph nodes utilizes the leukotriene $\mathrm{C} 4$ which in turn promotes chemotaxis to CCL19 and mobilization of DCs from the epidermis. In our study it is possible that during the laser capture microdissection procedure we captured DC cells that may be present and intermingled with the epithelia lining the ductal structure, otherwise we can assume that this gene product is expressed in the epithelial cells. Another chemokine (C-C motif) receptor 4 (CCR4) is also upregulated in the parous epithelia but only two-fold. CCR4 protein contains 3 potential N-glycosylation sites and multiple potential phosphorylation sites. This transcript has high levels in the thymus and peripheral blood leukocytes and lower levels in the spleen; no expression was detected in prostate, testis, ovary, small intestine, and colon (61). Its function in the breast epithelia is unknown but could be considered part of the signature of Stem cell 2 (Fig. 3).
The chemokine, CXC motif, ligand 11 (CXCL11) is not significantly different in parous and nulliparous breast epithelia, but the chemokine, CC motif, ligand 5 (CCL5) is 11-fold upregulated in the parous breast epithelia. This cytokine is also known as RANTES T cell-specific (62). RANTES is an acronym for Regulated upon Activation, Normally TExpressed, and presumably Secreted, suggesting that it constitutes a family of small, secreted T cell molecules. Cocchi et al (63) demonstrated that the chemokines RANTES, MIP-1$\alpha$, and MIP-1- $\beta$ are the major HIV-suppressive factors produced by CD8-positive T cells. Arenzana-Seisdedos et al (64) investigated a derivative of RANTES as a possible therapeutic agent for inhibition of HIV infection. Using astrocytes obtained from 5- to 10-week-old fetal forebrains and in situ hybridization and immunohistochemical analyses, it has been shown that expression of RANTES mRNA and protein, but not of other chemokines, increases with age and that RANTES inhibited proliferation and prolonged survival of wild-type cells but had no effect on $\mathrm{Ccr}^{-/-}$cells (65). The data strongly suggest that this chemokine is not only a mediator of inflammation, but also a significant regulator of differentiation in development. Ccl5-deficient mice had delayed viral clearance, excessive airway inflammation, and respiratory death after infection with either murine parainfluenza or human influenza viruses (66). CCL5 was required to hold apoptosis and mitochondrial dysfunction in check in virus-infected mouse macrophages in vivo and mouse and human macrophages ex vivo, and the protective effect of CCL5 required activation of CCR5 and the downstream ERK1 (MAPK3), ERK2 (MAPK1) and AKT signaling pathways. Therefore, CXCL11 may play an important role in the protective effect that has been attributed to pregnancy and hCG against HIV infection.

Interleukin-8 is more than 76-fold increased in the parous breast epithelial cells. Interleukin- 8 is one of a family of 13 human CXC chemokines $(67,68)$. This small basic heparanbinding protein was found in the human fallopian tube predominantly in the epithelial cells and was present in greater amounts in the distal compared with the proximal tube. IL8 is produced and released from human adipose tissue and from isolated adipocytes in vitro, which may indicate that IL8 from adipose tissue could be involved in some obesity-related complications. IL8 induces rapid mobilization of hematopoietic progenitor cells (HPCs) (69). We have shown herewith that IL8 is positively expressed in the cytoplasm of the parous breast epithelia, indicating that synthesis of the molecule takes place in situ and not by contamination of the intralobular or interlobular stroma. However, their role at the present time is not clear and it could be another host defense mechanism developed during pregnancy and persistent in the epithelial cells of the parous breast.

Of great interest is the upregulation of the interleukin $1 \beta$ (IL1ß) in the parous breast epithelia. IL1ß causes nuclear export of a specific NCOR corepressor complex, resulting in derepression of a specific subset of nuclear factor $\kappa \mathrm{B}$ $(\mathrm{NF \kappa B})$-regulated genes (70). These genes are exemplified by the tetraspanin KAI1, which regulates membrane receptor function. Nuclear export of the NCOR/TAB2/HDAC3 complex by IL $1 \beta$ is temporally linked to selective recruitment of a TIP60 coactivator complex. KAI1 is also directly activated by a ternary complex, dependent on the acetyltransferase 
activity of TIP60, that consists of the presenilin-dependent $\mathrm{C}$-terminal cleavage product of the $\beta$ amyloid precursor protein (APP; FE65, and TIP60), identifying a specific in vivo gene target of an APP-dependent transcription complex in the brain. Takahashi et al (71) found that IL1ß, a prominent microglia-derived cytokine, caused oligodendrocyte death in coculture with astrocytes and microglia, but not in pure culture of oligodendrocytes alone. Endogenous levels of Il1b induced hypoglycemia and triggered Il1b gene expression in the hypothalamus of normal and insulin-resistant mice; IL1ßinduced hypoglycemia was largely antagonized by blockade of Il1r1 in the brain (72). The function of this transcript is multifunctional and its precise role in the breast is unknown.

Selectin P (granule membrane protein $140 \mathrm{kDa}$, antigen CD62) is downregulated in the breast of parous epithelia. GMP140 (P-selectin), a 140-kDa granular membrane glycoprotein localized to the $\alpha$ granules of platelets and the Weibel-Palade bodies of endothelial cells, is thought to play an important role in adhesive interactions predominantly between granulocytes, platelets and vascular endothelial cells during inflammation. GMP-140 binds to chronically antigen (Ag)-stimulated $\mathrm{CD}^{4+}$ $\mathrm{T}$ cells. GMP-140 in conjunction with anti-T cell receptor $\alpha \beta$ monoclonal antibodies augmented the production of granulocyte-macrophage colony-stimulating factor GM-CSF and inhibited the production of interleukin- 8 by Ag-primed $\mathrm{T}$ cells without influencing their tumor necrosis factor- $\alpha$ production (73). The role in the breast epithelial is unknown.

Compared to Collagen IV, Fibronectin 1 (FN1) was significantly upregulated (26-fold) in the parous breast epithelia. FN1 or LETS is a glycoprotein of high molecular weight that was identified on the surface of fibroblasts by labeling with radioactive compounds or specific antibodies. The protein is absent or greatly reduced in many transformed cells. LETS is thought to have a role in cell adhesion, morphology, and surface architecture. Its absence is thought to have a causal role in the loss of contact inhibition of movement in transformed cells. Hepatocytes and smooth muscle cells have collagen receptors; most other cells depend on fibronectin for binding to collagen, laminin and chondronectin are related proteins. Bing et al (74) showed that fibronectin binds to $\mathrm{C} 1 \mathrm{q}$ in the same manner that it binds collagen. A major function of the fibronectins is in the adhesion of cells to extracellular materials such as solid substrata and matrices. Because fibronectin stimulates endocytosis and promotes the clearance of particulate material from the circulation, the results suggest that fibronectin functions in the clearance of $\mathrm{C} 1 \mathrm{q}$-coated material such as immune complexes or cellular debris (74). Sakai et al (75) demonstrated that fibronectin is essential for cleft formation during the initiation of epithelial branching. Fibronectin mRNA and fibrils appeared transiently and focally in forming cleft regions of submandibular salivary gland epithelia, accompanied by an adjacent loss of E cadherin localization. Decreasing the fibronectin concentration by using small interfering RNA (siRNA) and inhibition by anti-fibronectin or anti-integrin antibodies blocked cleft formation and branching. Exogenous fibronectin accelerated cleft formation and branching. Similar effects of fibronectin suppression and augmentation were observed in developing lung and kidney. Mechanistic studies revealed that fibrillar fibronectin can induce cell-matrix adhesions on cultured human salivary epithelial cells with a local loss of cadherins at cell-cell junctions. Thus, fibronectin expression in the parous breast epithelia may be related to branching morphogenesis associated with the conversion of cell-cell adhesions to cell-matrix adhesions. Altogether the overexpression of FN1 in parous breast epithelial cells is an indicator or marker of cell differentiation and is an important component of the genomic signature of Stem cell 2.

Prostaglandin-endoperoxide synthase 2 (PTGS2) is more than five-fold upregulated in the parous epithelia. PTGS2 is associated with biologic events such as injury, inflammation, and proliferation (76,77). Kirschenbaum et al (78) studied the immunohistochemical localization of PTGS2 in the human male fetal and adult reproductive tracts. In a prepubertal prostate there was some PTGS2 expression that localized exclusively to the smooth muscle cells of the transition zone. In adult hyperplastic prostates, PTGS2 was strongly expressed in smooth muscle cells, with no expression in the luminal epithelial cells. PTGS2 was strongly expressed in epithelial cells of both fetal and adult seminal vesicles and ejaculatory ducts. Zhou et al (79) found that culturing cells with highly purified human chorionic gonadotropin (hCG) resulted in a time- and dose-dependent increase in steady state levels of COX2 mRNA and protein and the secretion of prostaglandin E2 (PGE2). Although human luteinizing hormone could mimic hCG, follicle-stimulating hormone, thyroid-stimulating hormone, and the $\alpha$ (CGA) and $\beta$ (CGB) subunits of hCG had no effect on COX2 protein levels. The authors (79) concluded that hCG and LH treatment can increase expression of COX2 in human endometrial gland epithelial cells; the effect is time and dose dependent, hormone specific, and mediated by the cAMP/type I protein kinase A signaling pathway; the hCG actions require a normal complement of its receptors in cells; and these hCG and LH effects may be another action of these hormones in human endometrium that is important for implantation of the blastocyst and continuation of pregnancy. Because the parous breast epithelia has been under the influence of the hCG during pregnancy the overexpression of PTGS2 could be another marker of the Stem cell 2 induced by this hormone during pregnancy.

The data lead us to conclude that an early pregnancy, by shifting the Stem cell 1 to Stem cell 2, makes the latter more easily recognized by the immune-surveillance system, which initiates the programmed cell death pathway if exposure to toxic or carcinogenic agents occurs.

\section{Acknowledgements}

This study was supported by Grant RO1-CA093599 from the National Cancer Institute, USA

\section{References}

1. Russo J, Balogh GA, Chen J, Fernandez SV, Fernbaugh R, Heulings R, Mailo DA, Moral R, Russo PA, Sheriff F, Vanegas JE, Wang R and Russo IH: The concept of stem cell in the mammary gland and its implication in morphogenesis, cancer and prevention. Front Biosci 1: 151-172, 2006.

2. Russo J, Moral R, Balogh GA, Mailo D and Russo IH: The protective role of pregnancy in breast cancer. Breast Cancer Res 7: 131-142, 2005.

3. Balogh GA, Heulings R, Mailo DA, Russo PA, Sheriff F, Russo IH, Moral R and Russo J: Genomic signature induced by pregnancy in the human breast. Int J Oncol 28: 399-410, 2006. 
4. Russo J, Rivera R and Russo IH: Influence of age and parity on the development of the human breast. Breast Cancer Res Treat 23: 211-218, 1992.

5. Russo J and Russo IH: Development of human mammary gland. In: The Mammary Gland Development, Regulation, and Function. Neville MC and Daniel CW (eds). Plenum Pub. Corp, New York, pp67-93, 1987.

6. Russo J, Calaf G and Russo IH: A critical approach to the malignant transformation of human breast epithelial cells with chemical carcinogens. Crit Rev Oncog 4: 403-417, 1993.

7. Russo J and Russo IH: Role of differentiation on transformation of human epithelial cells. In: Cellular and Molecular Biology of Mammary Cancer. Medina D (ed). Plenum Press, New York, pp399-417, 1987.

8. Russo J and Russo IH: Role of differentiation in the pathogenesis and prevention of breast cancer. Endocrine-Related Cancer 4: $1-15,1997$

9. Livak KJ and Schmittgen TD: Analysis of relative gene expression data using real-time quantitative PCR and the 2-Delta Delta Ct Method. Methods 25: 402-408, 2001.

10. Benoy IH, Elst H, Van der Auwera I, Van Laere S, van Dam P, Van Marek E, Scharpe S, Vermeulen PB and Dirix LY: Realtime RT-PCR correlates with immunocytochemistry for the detection of disseminated epithelial cells in bone marrow aspirates of patients with breast cancer. Br J Cancer 91: 1813-1820, 2004.

11. Russo J and Russo IH: Toward a physiological approach to breast cancer prevention. Cancer Epidemiol Biomarkers Prev 3: 353-364, 1994

12. Russo $\mathrm{IH}$ and Russo J: Role of $\mathrm{hCG}$ and inhibition in breast cancer. Int J Oncol 4: 297-306, 1994.

13. Srivastava P, Russo J and Russo IH: Chorionic gonadotropin inhibits rat mammary carcinogenesis through activation of programmed cell death. Carcinogenesis 18: 1799-1808, 1997.

14. Srivastava P, Russo J and Russo IH: Inhibition of rat mammary tumorigenesis by human chorionic gonadotropin associated with increased expression of inhibin. Mol Carcinog 26: 10-19, 1999.

15. Boise, LH, Gonzalez-Garcia M, Postema CE, et al: bcl-x, a bcl-2 related gene that functions as a dominant regulator of apoptotic cell death. Cell 74: 597-608, 1993.

16. Falke D, Fisher MH and Juliano RL: Selective transcription of p53 target genes by zinc finger-p53 DNA binding domain chimeras. Biochim Biophys Acta 1681: 15-27, 2004.

17. Qin Q, Patil K and Sharma SC: The role of Bax-inhibiting peptide in retinal ganglion cell apoptosis after optic nerve transection. Neurosci Lett 372: 17-21, 2004.

18. Oltvai ZN, Milliman CL and Korsmeyer SJ: Bcl-2 heterodimerizes in vivo with a conserved homolog, $\mathrm{Bax}$, that accelerates programmed cell death. Cell 74: 609-619, 1993.

19. Bargou RC, Daniel PT, Mapara MY, et al: Expression of the bcl-2 gene family in normal and malignant breast tissue: low bax-expression in tumor cells correlates with resistance towards apoptosis. Int J Cancer 60: 854-859, 1995.

20. Russel, DL, Kaklamanis L, Pezzella F, Gatter KC and Harris AL: Bcl-2 in normal human breast and carcinoma, association with oestrogen receptor-positive, epidermal growth factor receptornegative turn ours and in situ cancer. Br J Cancer 69: 135-139, 1994.

21. Gasparini, G, Barbareschi M, Doglioni C, et al: Expression of Bcl-2 protein predicts efficacy of adjuvant treatments in operable nodepositive breast cancer. Clin Cancer Res 1: 189-198, 1995.

22. Krajewski S, Blomqvist C, Franssila K, et al: Reduced expression of proapoptotic gene bax is associated with poor response rates to combination chemotherapy and shorter survival in women with metastatic breast adenocarcinoma. Cancer Res 55: 4471-4478, 1995.

23. Bargou RC, Wagener C, Bommert K, et al: Overexpression of the death-promoting gene bax-OC which is downregulated in breast cancer restores sensitivity to different apoptotic stimuli and reduces tumor growth in SOD mice. J Clin Invest 97: 2651-2659, 1996.

24. Huang XY, Barrios LA, Vonkhorporn P, Honda S, Albertson DG and Hecht RM: Genomic organization of the glyceraldehyde-3phosphate dehydrogenase gene family of Caenorhabditis elegans. J Mol Biol 206: 411-424, 1989.

25. Dugaiczyk A, Haron JA, Stone EM, Dennison OE, Rothblum KN and Schwartz RJ: Cloning and sequencing of a deoxyribonucleic acid copy of glyceraldehyde-3-phosphate dehydrogenase messenger ribonucleic acid isolated from chicken muscle. Biochemistry 22: 1605-1613, 1983
26. Berry MD and Boulton AA: Glyceraldehyde-3-phosphate dehydrogenase and apoptosis. J Neurosci Res 60: 150-154, 2000.

27. Ernst WA, Thoma-Uszynski S and Teitelbaum R: Granulysin, a $\mathrm{T}$ cell product, kills bacteria by altering membrane permeability. J Immunol 165: 7102-7108, 2000.

28. Hanson DA, Kaspar AA, Poulain FR and Krensky AM Biosynthesis of granulysin, a novel cytolytic molecule. Mol Immunol 36: 413-422, 1999 .

29. Pena SV and Krensky AM: Granulysin, a new human cytolytic granule-associated protein with possible involvement in cellmediated cytotoxicity. Semin Immunol 9: 117-125, 1997.

30. Stenger S, Hanson DA and Teitelbaum R: An antimicrobial activity of cytolytic T cells mediated by granulysin. Science 282: 121-125, 1998 .

31. Kaspar AA, Okada S and Kumar J: A distinct pathway of cellmediated apoptosis initiated by granulysin. J Immunol 167: 350-356, 2001.

32. Wang Z, Choice E, Kaspar A, et al: Bactericidal and tumoricidal activities of synthetic peptides derived from granulysin. J Immunol 165: 1486-1490, 2000

33. Okada S, Li Q, Whitin JC, Clayberger C and Krensky AM: Intracellular mediators of granulysin-induced cell death. J Immunol 171: 2556-2562, 2003

34. Takamori Y, Ogawa K, Nagata K, Takano S and Nakamura M: Granulysin induces cell death with nuclear accumulation. J Med Dent Sci 52: 1-7, 2005

35. Huang LP, Lyu SC, Clayberger C and Krensky AM: Granulysinmediated tumor rejection in transgenic mice. J Immunol 178 : 77-84, 2007

36. Sasson R, Rimon E, Dantes A, Cohen T, Shinder V Land-Bracha A and Amsterdam A: Gonadotrophin-induced gene regulation in human granulosa cells obtained from IVF patients. Modulation of steroidogenic genes, cytoskeletal genes and genes coding for apoptotic signalling and protein kinases. Mol Hum Reprod 10: 299-311, 2004.

37. Kishi A, Takamori Y, Ogawa K, et al: Differential expression of granulysin and perforin by NK cells in cancer patients and correlation of impaired granulysin expression with progression of cancer. Cancer Immunol Immunother 50: 604-614, 2002.

38. Itoh N, Yonehara S, Ishii A, et al: The polypeptide encoded by the cDNA for human cell surface antigen Fas can mediate apoptosis. Cell 66: 233-243, 1991.

39. Oehm A, Behrmann I, Falk W, et al: Purification and molecular cloning of the APO-1 cell surface antigen, a member of the tumor necrosis factor/nerve growth factor receptor superfamily: sequence identity with the FAS antigen. J Biol Chem 267 10709-10715, 1992

40. Brunner T, Mogil RJ and LaFace D: Cell-autonomous Fas (CD95)/Fas-ligand interaction mediates activation-induced apoptosis in T-cell hybridomas. Nature 373: 441-444, 1995.

41. Ju ST, Panka DJ, Cui H, Ettinger R, El-Khatib M, Sherr DH, Stanger BZ and Marshak-Rothstein A: Fas(CD95)/FasL interactions required for programmed cell death after $\mathrm{T}$-cell activation. Nature 373: 444-448, 1995

42. Mannick JB, Hausladen A and Liu L: Fas-induced caspase denitrosylation. Science 284: 651-654, 1999.

43. Desbarats J, Birge RB, Mimouni-Rongy M, Weinstein DE, Palerme JS and Newell MK: Fas engagement induces neurite growth through ERK activation and p35 upregulation. Nature Cell Biol 5: 118-125, 2003.

44. Song E, Lee SK, Wang J, Ince N, Ouyang N, Min J, Chen J, Shankar P and Lieberman J: RNA interference targeting Fas protects mice from fulminant hepatitis. Nature Med 9: 347-351, 2003.

45. Ma Y, Liu H, Tu-Rapp H, Thiesen H-J, Ibrahim SM, Cole SM and Pope RM: Fas ligation on macrophages enhances IL-1R1Toll-like receptor 4 signaling and promotes chronic inflammation. Nature Immun 5: 380-387, 2004.

46. Laufer J, Oren R, Goldberg I, Afek A, Kopolovic J and Passwell JH: Local complement genes expression in the mammary gland: effect of gestation and inflammation. Pediatr Res 46: 608-612, 1999.

47. Abdulkadir SA, Krishna S, Thanos D, Maniatis T, Strominger JL and Ono SJ: Functional roles of the transcription factor Oct-2A and the high mobility group protein I/Y in HLA-DRA gene expression. J Exp Med 182: 487-500, 1995.

48. Sutherland DR, Watt SM, Dowden G, Karhi K, Baker MA, Greaves MF and Smart JE: Structural and partial amino acid sequence analysis of the human hemopoietic progenitor cell antigen CD34. Leukemia 2: 793-803, 1988. 
49. Sutherland DR, Stewart AK and Keating A: CD34 antigen: molecular features and potential clinical applications. Stem Cells 11 (suppl 3): 50-57, 1993.

50. Cheng J, Baumhueter S, Cacalano G, et al: Hematopoietic defects in mice lacking the sialomucin CD34. Blood 87: 479-490, 1996.

51. Okuno Y, Iwasaki H, Huettner CS, Radomska HS, Gonzalez DA, Tenen DG and Akashi K: Differential regulation of the human and murine CD34 genes in hematopoietic stem cells. Proc Natl Acad Sci 99: 6246-6251, 2002.

52. Simmons DL, Satterthwaite AB, Tenen DG and Seed B: Molecular cloning of a cDNA encoding CD34, a sialomucin of human hematopoietic stem cells. J Immun 148: 267-271, 1992.

53. Trowbridge IS and Thomas ML: CD45: an emerging role as a protein tyrosine phosphatase required for lymphocyte activation and development. Annu Rev Immunol 12: 85-116, 1994.

54. Pingel JT and Thomas ML: Evidence that the leucocyte-common antigen is required for antigen-induced $\mathrm{T}$ lymphocyte proliferation. Cell 58: 1055-1065, 1989.

55. Leitenberg D, Boutin Y, Lu DD and Bottomly K: Biochemical association of $\mathrm{CD} 45$ with the $\mathrm{T}$ cell receptor complex: regulation by CD45 isoform and during $\mathrm{T}$ cell activation. Immunity 10: 701-711, 1999.

56. Kishihara K, Penninger J, Wallace VA, et al: Normal B lymphocyte development but impaired $\mathrm{T}$ cell maturation in CD45-exon 6 protein tyrosine phosphatase deficient mice. Cell 74: 143-156, 1993

57. Byth KF, Conroy LA, Howlett S, Smith AJH, May J, Alexander DR and Holmes N: CD45-null transgenic mice reveal a positive regulatory role for CD45 in early thymocyte development, in the selection of CD4+CD8+ thymocytes and in B cell maturation. J Exp Med 183: 170, 1996.

58. Yoshida R, Imai T and Hieshima K: Molecular cloning of a novel human CC chemokine EBI1-ligand chemokine that is a specific ligand for EBI1, CCR7. J Biol Chem 272: 13803-13809, 1997.

59. Rossi DL, Vicari AP, Franz-Bacon K, McClanahan TK and Zlotnik A: Identification through bioinformatics of two new macrophage proinflammatory human chemokines. J Immun 158: 1033-1036, 1997.

60. Robbiani DF, Finch RA, Jager D, Muller WA, Sartorelli AC and Randolph GJ: The leukotriene C4 transporter MRP1 regulates CCL19 (MIP-3-beta, ELC)-dependent mobilization of dendritic cells to lymph nodes. Cell 103: 757-768, 2000.

61. Imai T, Baba M, Nishimura M, Kakizaki M, Takagi S and Yoshie O: The T cell-directed CC chemokine TARC is a highly specific biological ligand for CC chemokine receptor 4. J Biol Chem 272: 15036-15042, 1997.

62. Schall T, Jongstra J, Dyer B, Jorgenson J, Clayberger C, Davis MM and Krensky AM: The isolation and sequence of a novel gene from a human functional T cell line. J Immun 141: 1018-1025, 1988

63. Cocchi F, DeVico AL, Garzino-Demo A, Arya SK, Gallo RC and Lusso P: Identification of RANTES, MIP-1-alpha, and MIP-1-beta as the major HIV-suppressive factors produced by CD8(+) T cells. Science 270: 1811-1815, 1995.
64. Arenzana-Seisdedos F, Virelizier JL, Rousset D, Clark-Lewis I, Loetscher P, Moser B and Baggiolini M: HIV blocked by chemokine antagonist. Nature 383: 400, 1996.

65. Bakhiet M, Tjernlund A, Mousa A, Gad A, Stromblad S, Kuziel WA, Seiger A and Andersson J: RANTES promotes growth and survival of human first-trimester forebrain astrocytes. Nature Cell Biol 3: 150-157, 2001.

66. Tyner JW, Uchida O and Kajiwara N: CCL5-CCR5 interaction provides antiapoptotic signals for macrophage survival during viral infection. Nature Med 11: 1180-1187, 2005.

67. Modi WS and Chen ZQ: Localization of the human CXC chemokine subfamily on the long arm of chromosome 4 using radiation hybrids. Genomics 47: 136-139, 1998

68. Modi WS, Dean M, Matsushima K, Seuanez H and O'Brien SJ: Chromosome mapping and RFLP analyses of monocyte-derived neutrophil chemotactic factor (MDNCF/IL-8). Cytogenet Cell Genet 51: 1046a, 1989

69. Pruijt JFM, Verzaal P, van Os R, et al: Neutrophils are indispensable for hematopoietic stem cell mobilization induced by interleukin-8 in mice. Proc Natl Acad Sci 99: 6228-6233, 2002.

70. Baek SH, Ohgi KA, Rose DW, Koo EH, Glass CK and Rosenfeld MG: Exchange of N-CoR corepressor and Tip60 coactivator complexes links gene expression by NF-kappa-B and beta-amyloid precursor protein. Cell 110: 55-67, 2002.

71. Takahashi JL, Giuliani F, Power C, Imai Y and Yong VW: Interleukin-1-beta promotes oligodendrocyte death through glutamate excitotoxicity. Ann Neurol 53: 588-595, 2003.

72. del Rey A, Roggero E, Randolf A, Mahuad C, McCann S, Rettori V and Besedovsky HO: IL-1 resets glucose homeostasis at central levels. Proc Natl Acad Sci 103: 16039-16044, 2006.

73. Damle NK, Klussman K, Dietsch MT, Mohagheghpour N and Aruffo A: GMP-140 (P-selectin/CD62) binds to chronically stimulated but not resting CD4+ $\mathrm{T}$ lymphocytes and regulates their production of proinflammatory cytokines. Eur J Immunol 22: $1789-1793,1992$.

74. Bing DH, Almeda S, Isliker $\mathrm{H}$, Lahav $\mathrm{J}$ and Hynes RO Fibronectin binds to the C1q component of complement. Proc Natl Acad Sci 79: 4198-4201, 1982.

75. Sakai T, Larsen M and Yamada KM: Fibronectin requirement in branching morphogenesis. Nature 423: 876-881, 2003.

76. Hla T and Neilson K: Human cyclooxygenase-2 cDNA. Proc Natl Acad Sci 89: 7384-7388, 1992.

77. Tazawa R, Xu XM, Wu KK and Wang LH: Characterization of the genomic structure, chromosomal location and promoter of human prostaglandin $\mathrm{H}$ synthase-2 gene. Biochem Biophys Res Commun 203: 190-199, 1994.

78. Kirschenbaum A, Liotta DR and Yao S: Immunohistochemical localization of cyclooxygenase- 1 and cyclooxygenase- 2 in the human fetal and adult male reproductive tracts. J Clin Endocr Metab 85: 3436-3441, 2000.

79. Zhou XL, Lei ZM and Rao CV: Treatment of human endometrial gland epithelial cells with chorionic gonadotropin/luteinizing hormone increases the expression of the cyclooxygenase-2 gene. J Clin Endocr Metab 84: 3364-3377, 1999. 